\title{
Microanalysis of Two Members of Oxicam Drugs by Quenching the Fluorescence of Newly Isolated Carbonaceous Materials From Incense Ash
}

Mohamed Mohamed Salem Rizk.

Helwan University Faculty of Commerce

Emad Ramzy gadallah. abd el malak gadallah.

HU: Helwan University

nabil abdel ghany. manakhly

NRC egypt

Safaa shafik Toubar.

Helwan University

Marwa Helmy solliman ( $\nabla$ marwaibrahim46@yahoo.com )

Helwan University https://orcid.org/0000-0002-9839-4962

Research Article

Keywords: Tenoxicam, Meloxicam, Fluorescence, Sensor, Inner filter effect, Isolated CMTS

Posted Date: May 10th, 2021

DOI: https://doi.org/10.21203/rs.3.rs-461482/v1

License: (c) (i) This work is licensed under a Creative Commons Attribution 4.0 International License.

Read Full License

Version of Record: A version of this preprint was published at Journal of Fluorescence on July 27th, 2021. See the published version at https://doi.org/10.1007/s10895-021-02774-5. 


\section{Abstract}

For the first time ever, useful fluorescent (FL) carbonaceous materials (CMTS) were isolated from incense ash using facile procedure on two steps; dispersion of the CMTS in water followed by filtration. The CMTS were characterized using the following techniques; dynamic light scattering (DLS), transmission electron microscopy (TEM) and Fourier transform infrared (FT-IR) spectroscopy. The CMTS exhibit excitation wavelength dependent fluorescence emission, so it can be used as a FL probe. The FL probe was employed for sensing and quantitative determination of two members of oxicam family (tenoxicam (TEN) and meloxicam (MEL)) that belongs to non-steroidal anti-inflammatory drugs (NSAIDs). The method is based on the quenching of the FL intensity of the isolated CMTS by inner filter effect mechanism (IFE). The FL intensity decreases in linear relationship with the concentrations of the two cited drugs within the range of $4.0-30.0 \mu \mathrm{g} / \mathrm{mL}$ and mean percentage recoveries of $100.04 \pm 0.95$ and $100.07 \pm 1.06$ with detection limits of $1.31 \mu \mathrm{g} / \mathrm{mL}$ and $1.06 \mu \mathrm{g} / \mathrm{mL}$ for TEN and MEL , respectively. Finally, the developed sensing system was validated as per $\mathrm{ICH}$ guidelines and it was proved to be accurate and precise and applied successfully for quantitative determination of the two cited drugs in their capsule dosage forms with excellent percentage recoveries reaching to $97.66 \pm 0.39$ and $98.19 \pm 1.12$ for TEN and MEL, respectively.

\section{Introduction}

Tenoxicam (TEN) Fig. 1A and Meloxicam (MEL) Fig. 1B are nonsteroidal anti-inflammatory drugs (NSAID) that are members of oxicam family, and both of them can be used effectively as analgesic and antipyretic agents[1, 2]. The chemical formulas of TEN and MEL are (4- hydroxy-2-methyl-N-(2-pyridinyl)$2 \mathrm{H}$-thieno[2,3-e] [1, 2] thiazine-3-carboxamide-1,1- dioxide) and( 4 -hydroxy - 2 -methyl - $\mathrm{N}$-(5 -methyl - 1,3 -thiazol - 2 -yl) - $2 \mathrm{H}-1,2$-benzothiazine - 3 -carboxamide - 1,1 -dioxide), respectively. The oxicam compounds described pharmacologically as cyclooxygenase (COX) enzyme inhibitors which suppress the production of cyclic endoperoxides and subsequent prostaglandin, so they commonly utilized for the management of rheumatic diseases and musculoskeletal and joint disorders[3]. TEN is an official drug in the British Pharmacopeia (BP) and MEL is an official drug in B.P and the United States Pharmacopeia (USP). The B.P described an HPLC method for assaying both TEN and MEL in their dosage forms [4], also the USP described another HPLC method for assaying MEL in its dosage forms [5]. Numerous other analytical techniques have been described for determination of the two cited drugs including ; spectrophotometric methods [6, 7], spectrofluorimetric methods [6, 8], chromatographic methods [6, 9-14] and electrochemical methods [6,15-17]. Despite these techniques are sensitive and accurate, they are also suffering from some shortages, such as using expensive instruments, tedious operation procedures and time consuming. So the aim of this study is the development of a new not just sensitive and selective but also fast analytical method with facile, economic and eco-friendly procedures for analysis of the two drugs.

Today, carbon dots (CDs) have been in spotlight, it has many applications in the drug sensing field. The great advantages it exhibits in comparison with traditional semiconductor quantum dots and organic 
dyes such as low toxicity, biocompatibility, high optical absorptivity, excellent chemical stability, rich sources of inexpensive starting materials made the widespread applications of CDs in many fields including bio - imaging field [18]. Although CDs as a FL probes have been employed for sensing many drugs[19-21], up to till now, there is no any report on TEN and MEL determination using CDs as a FL probes.

\section{Experimental}

\subsection{Chemicals and materials}

\subsubsection{Standard samples}

TEN pure sample (100.144\%), kindly supplied by (EPICO company, Cairo, Egypt). MEL pure sample (100.010\%), kindly supplied by (Medical Union Pharmaceuticals (MUP) company, Cairo, Egypt). Both samples were used as supplied.

\subsubsection{Market samples}

Soral ${ }^{\circledR}$ capsule, batch number: $\mathrm{F} 23514$ with production date 12/2018 and expiration date 12/2021 (Global Napi pharmaceuticals company, Cairo, Egypt) labeled to contain $20 \mathrm{mg}$ of TEN. Anti Cox ${ }^{\circledR}$ capsule, batch number: 1910128 with production date 10 / 2018 and expiration date 7/2022 (Adwia pharmaceuticals company, Cairo, Egypt) labeled to contain $7.5 \mathrm{mg}$ MEL.

\subsubsection{Reagents}

Methanol HPLC grade ( Fisher Scientific, Germany ), copper (II) sulfate pentahydrate, calcium chloride dihydrate, zinc chloride, sodium chloride and potassium chloride ( Piochem company, Egypt ), cobalt(II) chloride hexahydrate, chromium(III) chloride hexahydrate (Merck, Darmstadt, Germany), potassium dihydrogen phosphate, sodium acetate, acetic acid (Riedel-de Haen, Seelze, Germany ) and sodium hydroxide (Sigma-Aldrich, Germany ) .

\subsection{Preparation of the isolated carbonaceous material}

The incense ashes were collected after burning the ARABESQUE incense sticks manufactured by (MO'MEN for fragrances and incense factory, industrial area, pieces No 19,20 -El Raswa - South Port Said - Egypt ) and stored in plastic bottles at room temperature. About $250.0 \mathrm{mg}$ of incense ashes were well dispersed in $250.0 \mathrm{~mL}$ deionized water and stirred for $15 \mathrm{~min}$ at $1000 \mathrm{rpm}$. Then the prepared solution was filtered using $0.2 \mu \mathrm{m}$ syringe filter and the resulted clear filtrate was stored in the refrigerator at $4^{\circ} \mathrm{C}$ for further study.

\subsection{Apparatus}

The functional groups of the isolated (CMTS) were recorded using a Fourier transform infrared spectrometer (JASCO FTIR, model: FT/IR- 4100 type A and serial number: B045461016) by preparing 
potassium bromide pellets. The UV - visible absorption spectra of the isolated (CMTS) was obtained using double beam JASCO (V-530) UV - Visible Spectrophotometer using 2 matched $1.0 \mathrm{~cm}$ quartz cuvettes. The fluorescence spectra and measurements were obtained on JASCO FP-6200 -

Spectrofluorimeter equipped with a $150 \mathrm{~W}$ xenon lamp and using $1.0 \mathrm{~cm}$ quartz cell, instrument excitation and emission slits were both adjusted to $10 \mathrm{~nm}$. Zetasizer (Malvern Zetasizer 2000), Malvern Instruments Ltd, Malvern, UKL, equipped with a video recorder was used for recording the Dynamic light scattering (DLS) to determine the size distribution profile of the isolated (CMTS). Transmission electron microscope (TEM) of model JEOL JEM-1230 with acceleration voltage $80 \mathrm{kV}$ was used to investigate the surface morphology and to measure the particle size of the isolated CMTS.

\subsection{Construction of the calibration curves of TEN and MEL}

Stock solutions of TEL and MEL were prepared by transferring accurately weighting $10.0 \mathrm{mg}$ of each drug to two $100 \mathrm{~mL}$ volumetric flasks. Each dissolved in $50.0 \mathrm{~mL}$ methanol and completed to the mark with the same solvent. To series of $10 \mathrm{~mL}$ stoppered volumetric flasks each contains $7.0 \mathrm{~mL}$ of the stock solution of the isolated CMTS, different aliquots from TEN stock solution were transferred then the flasks were completed to the mark with deionized water to give a final concentration range of 4.0-30.0 $\mu \mathrm{g}$ $\mathrm{TEN} / \mathrm{mL}$. The relative FL intensity was measured at $390 \mathrm{~nm}$ after excitation at $\lambda 295 \mathrm{~nm}$. The same procedures were constructed for MEL to give a final concentration range of 4.0-30.0 $\mu \mathrm{g} \mathrm{MEL} / \mathrm{mL}$. The final concentrations of the two cited drugs were plotted against the calculated FL quenching ratio (F0/F) to give the standard calibration curves. Instead the corresponding regression equations (Stern- Volmer equation) were derived.

\subsection{Analysis of TEN and MEL in their capsule dosage form}

For analysis of TEN in its capsule dosage form, the contents of not less than ten Soral ${ }^{\circledR}$ capsules (20 mg TEN/capsule) were weighted, accurately transferred to a suitable container and mixed well. An accurately weighed amount equivalent to $20 \mathrm{mg}$ of TEN was transferred to $100 \mathrm{~mL}$ volumetric flask, dissolved well with $50.0 \mathrm{~mL}$ methanol and sonicated using the ultrasonic water bath at $25^{\circ} \mathrm{c}$ for 15 minutes and completed to the mark with the same solvent. This solution was filtered using $0.45 \mu \mathrm{m}$ syringe filter with discarding the first few milliliters. The prepared solution is claimed to contain $200.0 \mu \mathrm{g} \mathrm{TEN} / \mathrm{mL}$. Different aliquots were withdrawn from the produced solution and were proceeded as mentioned under Sect. 2.4 to give a final concentrations that were claimed to contain 16.0, 20.0 and $30.0 \mu \mathrm{g} \mathrm{TEN} / \mathrm{mL}$. The same procedures were followed for determination of MEL in its capsule dosage form using not less than ten Anticox2® capsules ( $7.5 \mathrm{mg} \mathrm{MEL/capsule).} \mathrm{The} \mathrm{prepared} \mathrm{solution} \mathrm{is} \mathrm{claimed} \mathrm{to} \mathrm{contain} 75 \mu \mathrm{g}$ $\mathrm{MEL} / \mathrm{mL}$. Different aliquots were withdrawn from the prepared solution and were proceeded as mentioned under Sect. 2.4 to give a final concentrations that were claimed to contain 7.5, 15.0 and 22.5 $\mu \mathrm{g} \mathrm{MEL} / \mathrm{mL}$. The recoveries of the drug in all the prepared solutions were determined from the corresponding regression equations (Stern-Volmer equation).

\section{Results And Discussion}


Fortunately, despite the larger size of the simply isolated CMTS introduced in this work, it works in a similar way to the tediously prepared smaller CDs. This was obviously noticed during the characterization process using UV Visible spectroscopy, FTIR, TEM and DLS. Both TEN and MEL showed quenching behavior on the FL intensity of the isolated CMTS which was later proved to be caused by IFE mechanism. To optimize this sensing system different factors were studied to establish the optimum quantitative determination mechanism. Finally this sensing system was validated according to The ICH guidelines[22] and applied for determination of the two cited drugs in their capsules dosage form. Although it was found that most of the previously reported optical methods that were used for the analysis of the two cited drugs are more sensitive than our developed sensing system, they had suffered from many draw backs such as using expensive reagents and many highly toxic solvents, time consuming and narrow linear ranges as shown in the previously mentioned review article [6] and the previously reported work [8]. So the challenge which facing us in this work is the development of easy to use, eco-friendly and economic sensing system with wide range of linearity and reasonable sensitivity as illustrated in details in the following sections;

\subsection{Characterization of the isolated CMTS}

From numerous works in the literature, it was observed that some common optical characteristics of CDs and related materials have been mentioned for example, The UV-Visible spectra of the isolated CMTS showed maximum absorption peak at about $272 \mathrm{~nm}$ with a tail covering the visible region as shown in Fig. 2A. This is in agreement with that reported for colloidal CD absorption features[23]. Furthermore, as illustrated in Fig. 2B, upon increasing the excitation wavelength from 295 to $330 \mathrm{~nm}$, the FL emission peak moved to higher wavelengths while the $\mathrm{FL}$ intensity reduced. Such excitation-dependent emission behavior and the decline of the intensity are typical characteristics of CDs which result from a distribution of numerous emissive trap sites and the size distribution of the CDs[24]. Despite the larger size of the isolated CMTS introduced in this paper, it is found that it works in a similar way to CDs.

The central two features which are truthfully repeated in every type of CD are the functionalization layer on the surface which is characteristically very dense and disordered and the small size (10 nm or less) [25]. To study the structure of the isolated CMTS and the function groups present on its surface, Fourier transform infrared (FT-IR) spectroscopy was used and the produced spectrum showed numerous peaks related to the functionalities of the surface of the isolated CMTS particles, Fig. $2 \mathrm{C}$. The characteristic absorption peaks at $3450 \mathrm{~cm}-1,2990 \mathrm{~cm}-1,1500 \mathrm{~cm}-1,1350 \mathrm{~cm}-1,1100 \mathrm{~cm}-1$ and $900-690 \mathrm{~cm}-1$. The peaks at $3450 \mathrm{~cm}-1$ ascribed to the $-\mathrm{OH} / \mathrm{NH}$ whereas the peaks at $2990 \mathrm{~cm}-1,1500 \mathrm{~cm}-1,1350 \mathrm{~cm}-1$, $1100 \mathrm{~cm}-1$ and $900-690 \mathrm{~cm}-1$ assigned to the stretch vibration of $\mathrm{C}-\mathrm{H}$ aliphatic, stretching vibrations of conjugated $\mathrm{C}=\mathrm{C}$ in an aromatic heterocyclic ring, stretching vibrations of $\mathrm{C}-\mathrm{N}$, stretching vibrations of $\mathrm{C}-\mathrm{O}$ and asymmetric stretching vibrations of $\mathrm{C}-\mathrm{NH}-\mathrm{C}$, and bending vibrations of aromatic $=\mathrm{C}-\mathrm{H}$, respectively. These results were also reported for CDs [25]. Besides, it was established by DLS analysis that the gained beads showed a major peak at $161.8 \mathrm{~nm}$ as illustrated in Fig. 2D. The isolated CMTS behave similarly to CDs (10 nm or less) regardless its larger size, this observation matched with [23] \ Finally as shown in Fig. 2E, the (TEM) image of the isolated CMTS showed that the isolated CMTS were 
uniform, well detached from each other and had a close size of $161 \mathrm{~nm}$. All these findings prove that there is no need to follow the long and tedious procedures reported for preparing the small size CDs.

\subsection{Procedure for Optimization of Fluorescence Measurements}

Before using the developed FL probe, it was necessary to study and describe the optimal conditions for utilization. First, the FL intensity of the isolated CMTS was studied. To do so, different concentrations of CMTS were prepared from the stock solution that was prepared under Sect. 2.2 and their fluorescence intensity was measured at slit $10 \mathrm{~nm}$ after excitation at $295 \mathrm{~nm}$. This excitation wavelength attributed to the $n-\pi^{\star}$ transition of some connected groups which was closely related to the formation of the emissive traps and excited surface states resulting in strong FL intensity, this in agreement with $[24,26]$ and the FL intensity was recorded at $390 \mathrm{~nm}$ as illustrated in Fig. 3A. It was noticed that the CMTS emission was in linear relationship with the concentration of the CMTS from $50.0 \mu \mathrm{g} / \mathrm{mL}$ to $700.0 \mu \mathrm{g} / \mathrm{mL}$, after that negative deviation from this linear relationship was observed as illustrated in Fig. 3 ( $B, C)$. This may be attributed to possible self-absorbance of the emitted light would be occurred and the result was the selfquenching of the CMTS takes place. So maximum emission in $700.0 \mu \mathrm{g} / \mathrm{mL}$ concentration was utilized for all next measurements which provided more CMTS active sites [27]. Second, the interaction of the isolated CMTS with two members of oxicam group (TEN and MEL) was studied using spectrofluorimetry, and the obtained results showed that, both the two drugs under study quenched the fluorescence intensity of the isolated CMTS nearly with the same efficiency as illustrated in Fig. 3A. Concurrently, the effect of pH using $0.2 \mathrm{M}$ acetate buffer within the $\mathrm{pH}$ range from 3.6 to 5.8 and $0.2 \mathrm{M}$ phosphate buffer within the $\mathrm{pH}$ range from 6 to 8 on the structure of the isolated CMTS was studied using spectrofluorimetric measurements. Numerous CMTS solutions with various $\mathrm{pH}$ values were constructed and their FL intensities were determined. The FL intensity was determined for each sample and the results revealed that the FL intensity of the isolated CMTS was slightly increased at pH 3.6 to 4.6 then the $\mathrm{FL}$ intensity decreased beginning from $\mathrm{pH} 4.8$ to 8 as shown in Fig. 3D. Also the quenching efficiency of the two cited drugs was studied in absence and presence of the acetate buffer at pH 3.6 and the results showed that there was no significance difference in the FL quenching produced by each of the two cited drugs at various pHs studied. So the effect of buffer is neglected and measurements were constructed without using buffer. It is an important to take into consideration the development of a probe of fast response for quantitative determination of the two drugs, so the response time was examined and the results revealed that after first estimation there was no significant variation was established in $\mathrm{FL}$ quenching as shown in Fig. 4A. So, it was established that, this technique could be utilized for fast quantitative analysis of the two cited drugs, so this method can save the time required for the analysis process. The stability of the stock solution of the isolated CMTS was studied within 5 weeks by measuring the FL intensity. The results are shown in Fig. 4B, approving the suitability of the developed probe for routineanalysis.

\subsection{Validation of the method}




\subsubsection{Linearity and Possible Mechanism}

The FL spectra of the isolated CMTS were examined upon individually increasing the concentration of each of the two drugs under study and recording spectra after each concentration, the FL intensity of the isolated CMTS was gradually declined by increasing the concentration of each drug over a concentration range from $4.0 \mu \mathrm{g} / \mathrm{mL}$ to $30.0 \mu \mathrm{g} / \mathrm{mL}$ for both drugs under study with low limits of detection equal to $1.31 \mu \mathrm{g} / \mathrm{mL}$ and $1.06 \mu \mathrm{g} / \mathrm{mL}$ for TEN and MEL, respectively as shown in Fig. 5 and Table 1. FL spectra revealed that, by increasing the concentration of the drugs individually, the maximum emission wavelength of the isolated CMTS shifted to higher wavelengths (red shift) by about $28 \mathrm{~nm}$ ( $390 \mathrm{~nm}$ to $418 \mathrm{~nm})$ for TEN as shown in Fig. $5 \mathrm{~A}$ and by about $25 \mathrm{~nm}(390 \mathrm{~nm}$ to $415 \mathrm{~nm})$ for MEL as illustrated in Fig. $5 B$, this observation may be due to the inner filter effect quenching mechanism and this matched with[27]. As shown in Fig. 3A and Fig. 5 (A,B), the presence of TEN or MEL can efficiently quench the FL emission intensity of the isolated CMTS. To elucidate the quenching mechanism of each of the two cited drugs, some important properties of the isolated CMTS, TEN and MEL were investigated to lighten the sensing principle. For confirming the FL quenching mechanism ascribed to the IFE, related studies were done. It was obvious that the absorption spectra of TEN and MEL had great overlaps over the emission spectrum of the isolated CMTS as shown in Fig. 6A as a result, the IFE happened and the FL of isolated CMTS was quenched due to the competitive absorption[28]. Besides, the absorption spectra of the two drugs under study are not affected by the presence of the isolated CMTS as shown in Fig. 6 (B, C) revealing that there is no complex formed between the isolated CMTS and any of the two drugs under study. These results excluded the probability of fluorescence resonance energy transfer (FRET) quenching mechanism in this sensing process, this also matched with [29].

\subsubsection{Accuracy and precision}

The inter-day and intra-day precisions were assessed through replicate analysis of the two drugs under study in pure form using various concentrations and each concentration was determined three times per day for three successive days. The precision of the developed method was properly high, as designated by the small values of SD as shown in Table 2 . The accuracy of the proposed method was evaluated using various concentrations corresponding to the two cited drugs in pure form and capsule dosage form, the mean recoveries of three replicate determinations and the low SD revealed that the proposed method is accurate as illustrated in Table 3. This accuracy was further proved by applying the standard addition technique by spiking the content of the capsules equivalent to one capsule for each of the two drugs under study by different amounts of standards at level 50,100 and $150 \%$. The results showed good recoveries of the two drugs each in its capsule dosage form with low SD as shown in Table 4.

\subsubsection{Selectivity of the Sensing System}

To examine the selectivity of our system for sensing TEN and MEL, the FL response of this sensing system with most of the common ions such as $\mathrm{Ca}^{2+}, \mathrm{Co}^{2+}, \mathrm{Zn}^{2+}, \mathrm{Cu}^{2+}, \mathrm{Cr}^{3+}, \mathrm{K}^{+}$and $\mathrm{Na}^{+}$was determined under the same sensing conditions. The results revealed that there was no noticeable FL variations in the 
existence of the listed ions as illustrated in Fig. 6 (D, E). Furthermore the capsules excipients do not show any interference to the sensing of the two drugs in their capsules dosage form, this was proved by applying the standard addition technique and comparing the recoveries of the two cited drugs in their capsules dosage form obtained using the proposed sensing system and the official HPLC methods in the $\mathrm{BP}$ [4]. The results obtained from the standard addition technique and the comparison with the official methods revealed that there was no significant interference from the capsules excipients as illustrated in Tables 4 and 5.

\subsection{Application}

\subsubsection{Analysis of pharmaceutical formulations}

The developed sensing system was applied for quantitative analysis of TEN and MEL in their capsule dosage forms. The results are illustrated in Tables 3 and 4 . The results of the developed and reported methods [4] were statistically compared using the Student's $t$-test and variance ratio F-test. The results revealed that There were no significant differences between the two methods at $P=0.05$ as shown in Table 5, and hence the proposed sensing system is as accurate and precise as the corresponding reported method.

Table 1

Performance data for the two drugs under study using the proposed sensing system.

\begin{tabular}{|lll|}
\hline Parameter & TEN & MEL \\
\hline Linear range $(\mu \mathrm{g} / \mathrm{mL})$ & $4.0-30.0$ & $4.0-30.0$ \\
\hline Mean\% recovery & 100.04 & 100.07 \\
\hline S.D & 0.95 & 1.06 \\
\hline Relative standard deviation $(\% \mathrm{RSD})$ & 0.95 & 1.06 \\
\hline Regression equation & $\mathrm{F} 0 / \mathrm{F}=0.142 \mathrm{C}+0.9629$ & $\mathrm{~F} 0 / \mathrm{F}=0.0943 \mathrm{C}+0.8598$ \\
\hline Square correlation coefficient $\left(\mathrm{R}^{2}\right)$ & 0.9998 & 0.9999 \\
\hline S.D of intercept & 0.06 & 0.03 \\
\hline Limit of quantitation $(\mathrm{LOQ})(\mu \mathrm{g} / \mathrm{mL})$ & 3.97 & 3.23 \\
\hline Limit of detection $(\mathrm{LOD})(\mu \mathrm{g} / \mathrm{mL})$ & 1.31 & 1.06 \\
\hline
\end{tabular}

F0: fluorescence of CMTS in absence of the drug

F: fluorescence of CMTS in presence of the drug

$\mathrm{C}=$ Concentration in $\mu \mathrm{g} / \mathrm{mL}$ 
Table 2 Precision data for the two cited drugs using the developed sensing system .

\begin{tabular}{|c|c|c|c|c|c|c|}
\hline \multicolumn{7}{|c|}{ Intra -day precision } \\
\hline Drug & TEN & & & MEL & & \\
\hline Conc ( $\mu \mathrm{g} / \mathrm{mL})$ & 8.0 & 12.0 & 24.0 & 8.0 & 12.0 & 24.0 \\
\hline$\%$ Recovery $^{\star}$ & 98.50 & 99.10 & 98.8 & 99.50 & 99.20 & 98.70 \\
\hline SD & 0.30 & & & 0.40 & & \\
\hline \multicolumn{7}{|c|}{ Inter -day precision } \\
\hline Drug & TEN & & & MEL & & \\
\hline Conc ( $\mu \mathrm{g} / \mathrm{mL})$ & 8.0 & 12.0 & 24.0 & 8.0 & 12.0 & 24.0 \\
\hline$\%$ Recovery ${ }^{*}$ & 98.50 & 98.10 & 99.8 & 99.50 & 100.29 & 101.30 \\
\hline SD & 0.89 & & & 0.90 & & \\
\hline
\end{tabular}

* Average of three separate determinations 
Table 3

Accuracy of the proposed sensing system for the determination of the two drugs in pure drugs and in their capsules dosage form.

\begin{tabular}{|c|c|c|c|c|c|c|}
\hline \multicolumn{7}{|c|}{ Intra -day precision } \\
\hline Drug & TEN & & & MEL & & \\
\hline Conc $(\mu \mathrm{g} / \mathrm{mL})$ & 8.0 & 12.0 & 24.0 & 8.0 & 12.0 & 24.0 \\
\hline$\%$ Recovery* & 98.50 & 99.10 & 98.8 & 99.50 & 99.20 & 98.70 \\
\hline SD & 0.30 & & & 0.40 & & \\
\hline \multicolumn{7}{|c|}{ Inter -day precision } \\
\hline Drug & TEN & & & MEL & & \\
\hline Conc $(\mu \mathrm{g} / \mathrm{mL})$ & 8.0 & 12.0 & 24.0 & 8.0 & 12.0 & 24.0 \\
\hline$\%$ Recovery ${ }^{*}$ & 98.50 & 98.10 & 99.8 & 99.50 & 100.29 & 101.30 \\
\hline SD & 0.89 & & & 0.90 & & \\
\hline \multicolumn{7}{|l|}{ Pure drugs } \\
\hline Drug & TEN & & & MEL & & \\
\hline Conc $(\mu \mathrm{g} / \mathrm{mL})$ & 16.0 & 20.0 & 30.0 & 7.5 & 15.0 & 22.5 \\
\hline Found $^{*}$ & 15.75 & 19.82 & 29.98 & 7.40 & 14.90 & 22.38 \\
\hline$\%$ Recovery & 98.46 & 99.10 & 99.93 & 98.67 & 99.33 & 99.47 \\
\hline Mean \% recovery & 99.16 & & & 99.16 & & \\
\hline S.D & 0.74 & & & 0.43 & & \\
\hline$\%$ RSD & 0.74 & & & 0.43 & & \\
\hline \multicolumn{7}{|l|}{ Dosage form } \\
\hline Drug & TEN & & & MEL & & \\
\hline Conc $(\mu \mathrm{g} / \mathrm{mL})$ & 16.0 & 20.0 & 30.0 & 7.5 & 15.0 & 22.5 \\
\hline Found $^{*}$ & 15.58 & 19.62 & 29.25 & 7.37 & 14.89 & 21.84 \\
\hline$\%$ Recovery & 97.36 & 98.10 & 97.51 & 98.23 & 99.28 & 97.05 \\
\hline Mean \% recovery & 97.66 & & & 98.19 & & \\
\hline S.D & 0.39 & & & 1.12 & & \\
\hline$\%$ RSD & 0.39 & & & 1.12 & & \\
\hline
\end{tabular}


Table 4

Accuracy of the developing sensing system by standard addition technique in their capsules dosage form.

\begin{tabular}{|c|c|c|c|c|}
\hline Drug & Conc $(\mu \mathrm{g} / \mathrm{mL})$ & Amount added $(\mu \mathrm{g} / \mathrm{mL})$ & Found $^{*}(\mu \mathrm{g} / \mathrm{mL})$ & \% Recovery* \\
\hline \multirow[t]{6}{*}{ TEN } & 8.0 & 4.0 & 11.82 & 98.49 \\
\hline & & 8.0 & 16.01 & 100.04 \\
\hline & & 12.0 & 20.09 & 100.45 \\
\hline & Mean \% recovery & 99.66 & & \\
\hline & SD & 1.03 & & \\
\hline & $\%$ RSD & 1.03 & & \\
\hline Drug & Conc $(\mu \mathrm{g} / \mathrm{mL})$ & Amount added $(\mu \mathrm{g} / \mathrm{mL})$ & Found $^{*}(\mu \mathrm{g} / \mathrm{mL})$ & \% Recovery* \\
\hline \multirow[t]{6}{*}{ MEL } & 7.5 & 3.75 & 11.45 & 101.81 \\
\hline & & 7.5 & 15.45 & 102.97 \\
\hline & & 11.25 & 18.85 & 100.53 \\
\hline & Mean \% recovery & 101.77 & & \\
\hline & SD & 1.22 & & \\
\hline & \%RSD & 1.22 & & \\
\hline
\end{tabular}


Table 5

The statistical analysis of the results obtained using the developed sensing system and the reported HPLC [4] methods for analysis of the two drugs in their capsules dosage form.

\begin{tabular}{|lllll|}
\hline Method & \multicolumn{2}{l}{ Developed method } & Reported HPLC methods [ 4] \\
\hline Drug & TEN & MEL & TEN & MEL \\
\hline Mean \% recovery ${ }^{\mathrm{a}}$ & 97.66 & 98.19 & 98.60 & 98.40 \\
\hline $\mathrm{N}$ & 3 & 3 & 3 & 3 \\
\hline SD & 0.39 & 1.12 & 0.92 & 1.11 \\
\hline Student's t- test $(2.776)^{\mathrm{b}}$ & 1.64 & 0.22 & & \\
\hline Variance ratio F- test $(19.00)^{\mathrm{b}}$ & 5.49 & 2.79 & & \\
\hline a Average of three separate determination . & & & \\
\hline b Tabulated t and F at $\mathrm{P}=0.05$. & & & \\
\hline
\end{tabular}

\section{Conclusion}

For the first time, a fluorescent CMTS were isolated from the incense ash using very simple procedures based on the dispersion in deionized water and filtration. This simply isolated CMTS behave in similar manner as CDs, despite its bigger size compared with the previously reported synthetized CDs which made the present sensing system based on this isolated CMTS very simple and economic .Furthermore, this fluorescence sensor, has wonderful advantages such as low toxicity, stable photoluminescence, excellent solubility and chemically inertness. The isolated CMTS were successfully employed for assaying the TEN and MEL in their capsule dosage forms with achieving excellent percentage recoveries. The analytical method based on this sensing system was validated according to the ICH guidelines which proved its suitability as a sensing system for assaying the two drugs under study in their pure forms and their capsule dosage forms .Moreover, the developed sensing system had been proved to have a fast response and a reasonable selectivity towards the two drugs under study. Finally, it is essential to mention that this research can be considered as evidence for the presence of analytically beneficial materials in ashes. By the way, ashes from various sources should be also considered and further investigated.

\section{Declarations}

Availability of Data and Materials: applicable.

Authors' Contributions: All authors contributed to the study conception and design. Material preparation, data collection and analysis were performed by [Mohamed mohamed salem], [Nabil Abdul ghany], [Safaa 
shafike toubar] and [Marwa ibrahim hemy soliman]. The first draft of the manuscript was written by [Emad ramzy abd el malak] and all authors commented on previous versions of the manuscript. All authors read and approved the final manuscript.

Funding: This research did not receive any specific grant from funding agencies in the public, commercial, or not-for-profit sectors.

Code Availability: Not applicable.

Conflict of Interest: All authors declare that they have no conflict of interest.

\section{References}

[1] Unlu Z, Ay K, Tuzun C (2006) Comparison of intra-articular tenoxicam and oral tenoxicam for pain and physical functioning in osteoarthritis of the knee. Clin. Rheumatol. 25 : 54-61. https://doi.org/10.1007/s10067-005-1136-3.

[2] Bekker A, Kloepping C, Collingwood S (2018) Meloxicam in the management of post-operative pain: Narrative review. J. Anaesthesiol. Clin. Pharmacol. 34: 450-457. https://doi.org/10.4103/joacp.JOACP_133_18.

[3] Xu S, Rouzer CA, Marnett LJ (2014) Oxicams, a class of nonsteroidal anti-inflammatory drugs and beyond.IUBMB Life. 66 : 803-811. https://doi.org/10.1002/iub.1334.

[4] British Pharmacopoeia Commission. (2018). British Pharmacopoeia 2019 Edition.

[5] Pharmacopoeia US. United States pharmacopoeia and national formulary (USP 41-NF 36). InRockville, MD: United States pharmacopoeial convention 2018.

[6] Starek M, Krzek J (2009) A review of analytical techniques for determination of oxicams, nimesulide and nabumetone.Talanta. 77: 925-942.https://doi.org/10.1016/j.talanta.2008.09.022.

[7] Gurupadayya BM,.Trinath M N \& Shilpa K (2013) Spectrophotometric determination of meloxicam by sodium nitroprusside and 1,10-phenanthroline reagents in bulk and its pharmaceutical formulation.Indian J. Chem. Technol. 111-115.

[8] Tian J, Li C, Liu S, Liu Z, Yang J, Zhu J, Hu X (2014) A rapid and highly sensitive fluorimetric method for the determination of meloxicam using uranyl acetate.Anal. Methods. $6: 5221-5226$. https://doi.org/10.1039/c4ay00809j.

[9] Semreen MH, Aboul-Enein HY (2010) Lc-uv method development and validation for the non steroidal anti-inflammatory agent tenoxicam. J. Liq. Chromatogr. Relat. Technol. $33: 720-729$. https://doi.org/10.1080/10826071003609015. 
[10] Starek M and Krzek J (2012) TLC determination of meloxicam in tablets and after acidic and alkaline hydrolysis. Acta Pol. Pharm. Drug Res. 225-235.

[11] Tian Y, Wu X, Zhang M, Zhao L, Xiong Z, Qin F (2018) Quantitative determination of meloxicam in dog plasma by high performance liquid chromatography-tandem mass spectrometry and its application in a pharmacokinetic study. Biomed. Chromatogr. 32: e4228. https://doi.org/10.1002/bmc.4228.

[12] Lee HW, Ji HY, Kim HY, Lee K.C, Lee HS (2009) Liquid chromatography-Tandem mass spectrometry method for the determination of meloxicam and its metabolite 5-carboxymeloxicam in human plasma.Bioanalysis. 1: 63-70. https://doi.org/10.4155/bio.09.10.

[13] Cox S, Bailey J, White M, Gordon K and Souza M (2017) Determination of Meloxicam in Egg Whites and Yolks Using Reverse Phase Chromatography. J. Chromatogr. Sci. 55: 610-616.

[14] Leal LB, Bedor DC,. Melo EK, Oliveira EJ, Santana DP (2011) Determination of meloxicam in human plasma administrated with four drugs by LC method: application to a pilot bioavailability study, Lat. Am. J. Pharm. 30.

[15] Sadikoglu M, Cabuk A (2019) Voltammetric Determination of Tenoxicam in Drug Formulation at Modified Glassy Carbon Electrode. Int. J. Electrochem. Sci. 14: 4508-4519. https://doi.org/10.20964/2019.05.08.

[16] Eroğlu ME, Bayraktepe DE, Polat K, Yazan Z (2018) Electro-Oxidation Mechanism of Meloxicam and Electrochemical Sensing Platform Based on Graphene Nanoparticles for its Sensing Pharmaceutical Sample.Curr. Pharm. Anal. 15: 346-354. https://doi.org/10.2174/1573412914666180402130716.

[17] Šelešovská R, Hlobeňová F, Skopalová J, Cankař P, Janíková L, Chýlková J (2020) Electrochemical oxidation of anti-inflammatory drug meloxicam and its determination using boron doped diamond electrode.J. Electroanal. Chem. 858 : 113758. https://doi.org/10.1016/j.jelechem.2019.113758.

[18] Sciortino A, Cannizzo A, Messina F (2018) Carbon Nanodots: A Review-From the Current Understanding of the Fundamental Photophysics to the Full Control of the Optical Response. C - J. Carbon Res. 4: 67. https://doi.org/10.3390/c4040067.

[19] Amin N, Afkhami A, Hosseinzadeh L \& Madrakian T (2018)cost-effective synthesis of carbon dots from date kernel and their application as a novel switchable fluorescence probe for sensitive assay of Zoledronic acid drug in human serum and cellular imaging.Anal. Chim. Acta. 1030:183-193.

[20] Zhang Y, Gao Z, Zhang W, Wang W, Chang J\& Kai J (2018) Fluorescent carbon dots as nanoprobe for determination of lidocaine hydrochloride.Sensors Actuators B Chem. 262:928-937.

[21] Ghafarloo A, Sabzi RE, Samadi N \& Hamishehkar H (2020) Sensitive and selective spectrofluorimetric determination of clonazepam using nitrogen-doped carbon dots, J. Photochem. Photobiol. A Chem. 388 :112197. 
[22] ICH Harmonized Tripartite Guideline, Validation of analytical procedures: Text and

methodology, Q2(R1), Current Step 4 Version, Parent Guid lines on Methodology

Dated November 6, 1996, Incorporated in November 2005. http://www.lch.org/ LOB/

media/MEDIA417.pdf.

[23] Díaz-Álvarez M, Martín-Esteban A (2020) Fluorescent carbonaceous materials isolated from cigarette ashes for the determination of iron(iii) in water samples.Anal. Methods. $12: 3523-3529$. https://doi.org/10.1039/d0ay01091j.

[24] Lecroy GE, Messina F, Sciortino A, Bunker CE, Wang P, Fernando KAS, Sun YP (2017) Characteristic Excitation Wavelength Dependence of Fluorescence Emissions in Carbon "quantum" Dots. J. Phys. Chem. C. 121: 28180-28186. https://doi.org/10.1021/acs.jpcc.7b10129.

[25] Sciortino A, Cayuela A, Soriano ML, Gelardi FM, Cannas M, Valcárcel M\& Messina F (2017) Different natures of surface electronic transitions of carbon nanoparticles, Phys. Chem. Chem. Phys. $19: 22670-$ 22677.

[26] Song Y, Zhu C, Song J, Li H, Du D, Lin Y (2017) Drug-Derived Bright and Color-Tunable N-Doped Carbon Dots for Cell Imaging and Sensitive Detection of Fe3+ in Living Cells, ACS Appl. Mater. Interfaces. 9 : 7399-7405. https://doi.org/10.1021/acsami.6b13954.

[27] Wang X, Liu Y, Zhou Q, Sheng X, Sun Y, Zhou B, Zhao J, Guo J (2020) A reliable and facile fluorescent sensor from carbon dots for sensing 2, 4, 6-trinitrophenol based on inner filter effect,Science of The Total Environment.720:137680.

[28] Chen S, Yu YL, Wang JH (2018) Inner filter effect-based fluorescent sensing systems: A review, Anal. Chim. Acta. 999 : 13-26. https://doi.org/10.1016/j.aca.2017.10.026.

[29] Chen C , Zhao D, Hu T, Sun J, \& Yang X (2017) Highly fluorescent nitrogen and sulfur co-doped graphene quantum dots for an inner filter effect-based cyanide sensor, Sensors Actuators B Chem. 241 : 779-788.

\section{Figures}



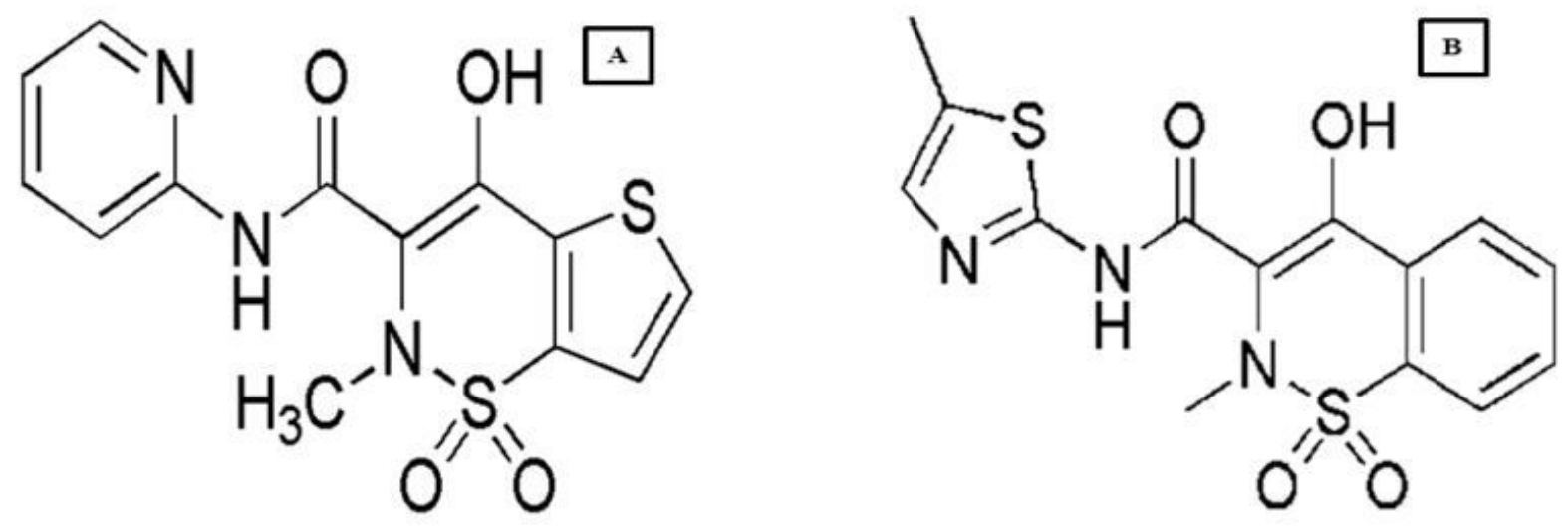

Figure 1

1Chemical structures of (A) TEN and (B) MEL. 

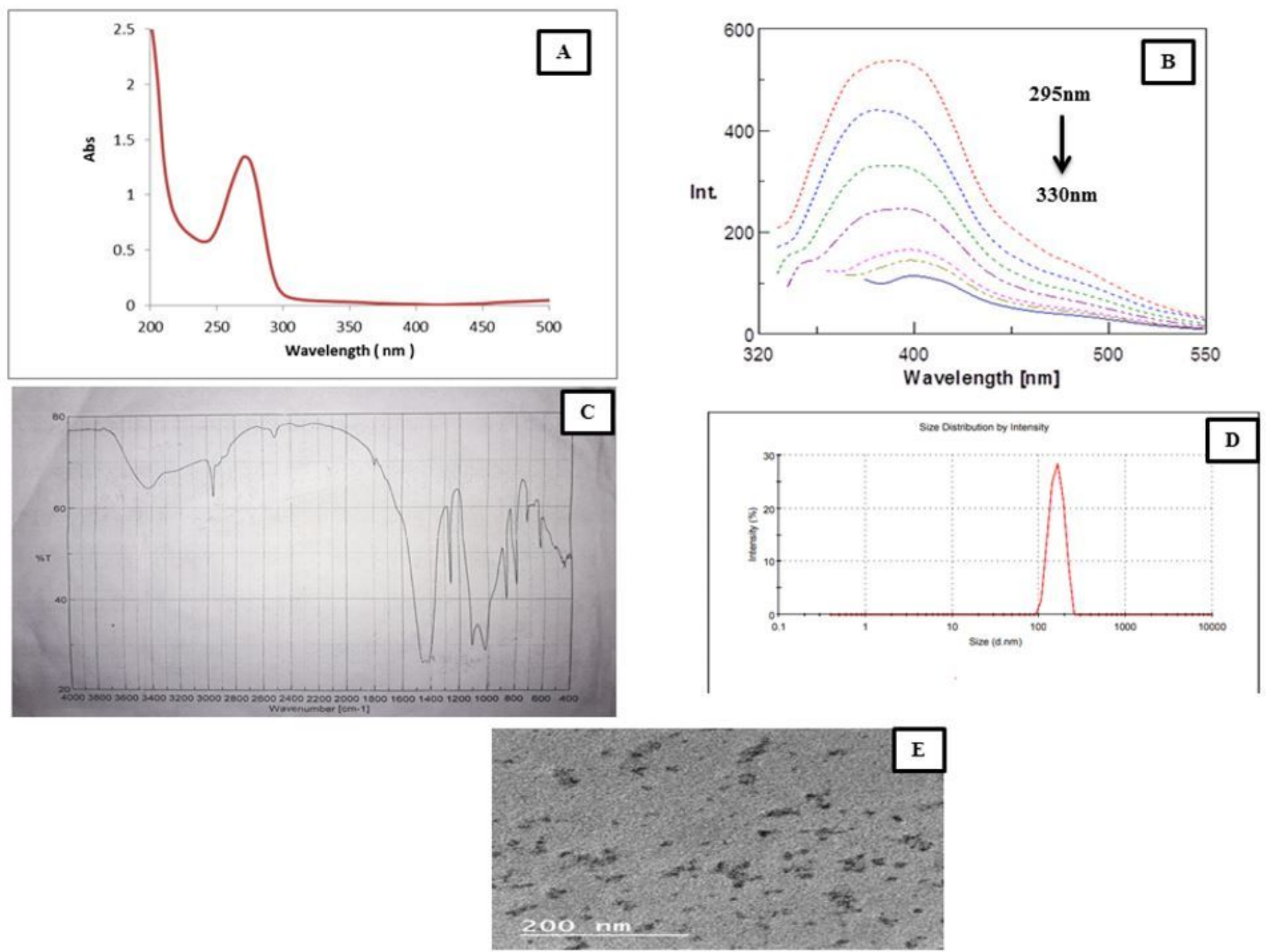

Figure 2

(A) Absorption spectrum of the isolated CMTS, (B) Fluorescence spectra of the isolated CMTS vs. various excitation wavelengths at room temperature, (C) FT-IR spectra of the isolated CMTS, (D) Size distribution histogram of the isolated CMTS using DLS analysis and (E) TEM image of the isolated CMTS. 

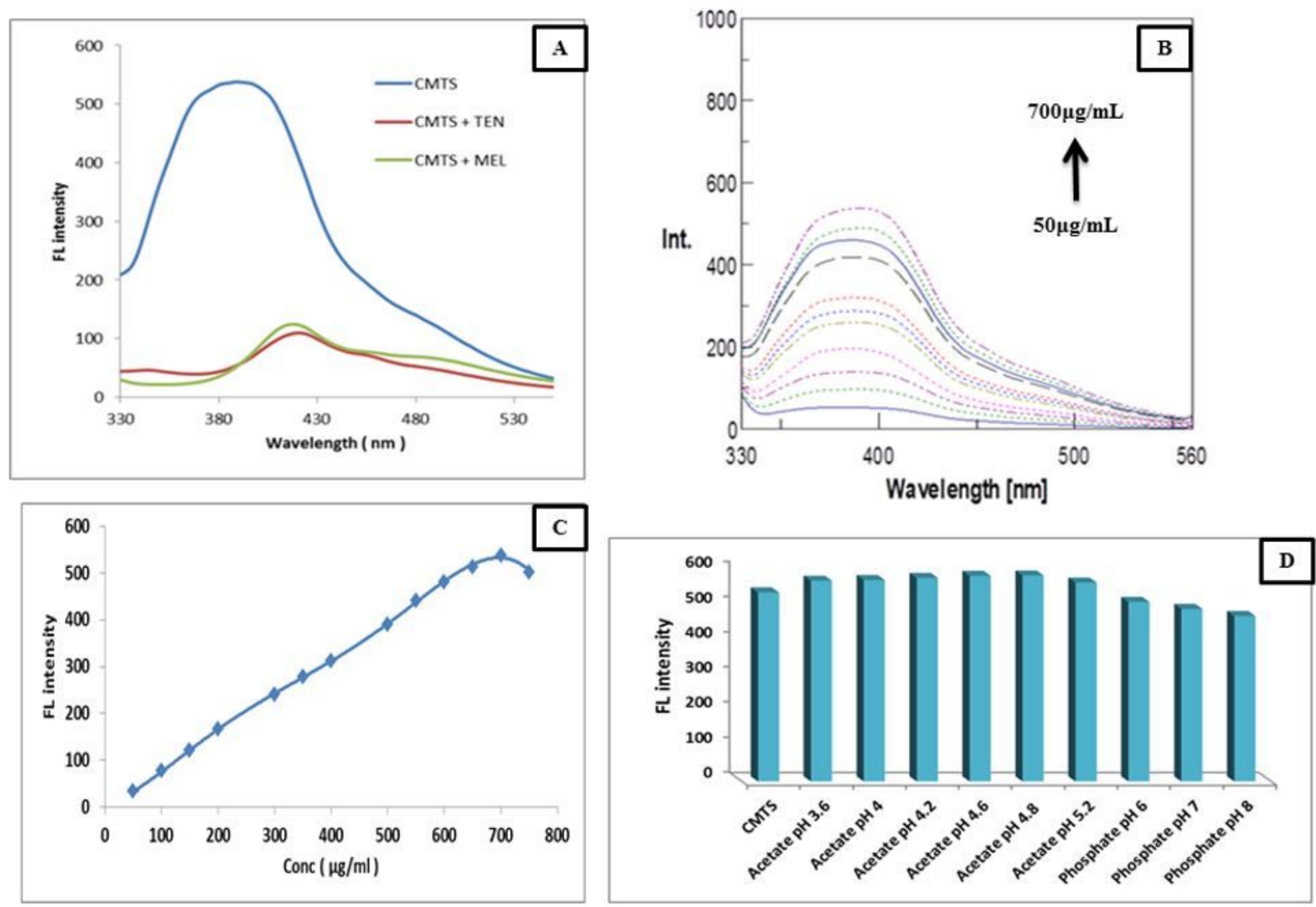

\section{Figure 3}

(A) Fluorescence intensity of the isolated CMTS, the isolated CMTS $+30.0 \mu \mathrm{g} / \mathrm{mL}$ TEN and the isolated $\mathrm{CMTS}+30.0 \mu \mathrm{g} / \mathrm{mL}$ MEL, (B) Emission spectrum overlay of different concentrations of the isolated CMTS upon increasing the concentration from $50.0 \mu \mathrm{g} / \mathrm{mL}$ to $700.0 \mu \mathrm{g} / \mathrm{mL}$ from bottom to top, (C) Fluorescence emission at different concentrations of The isolated CMTS and (D) Fluorescence intensity of the isolated CMTS at different $\mathrm{pH}$ levels. 

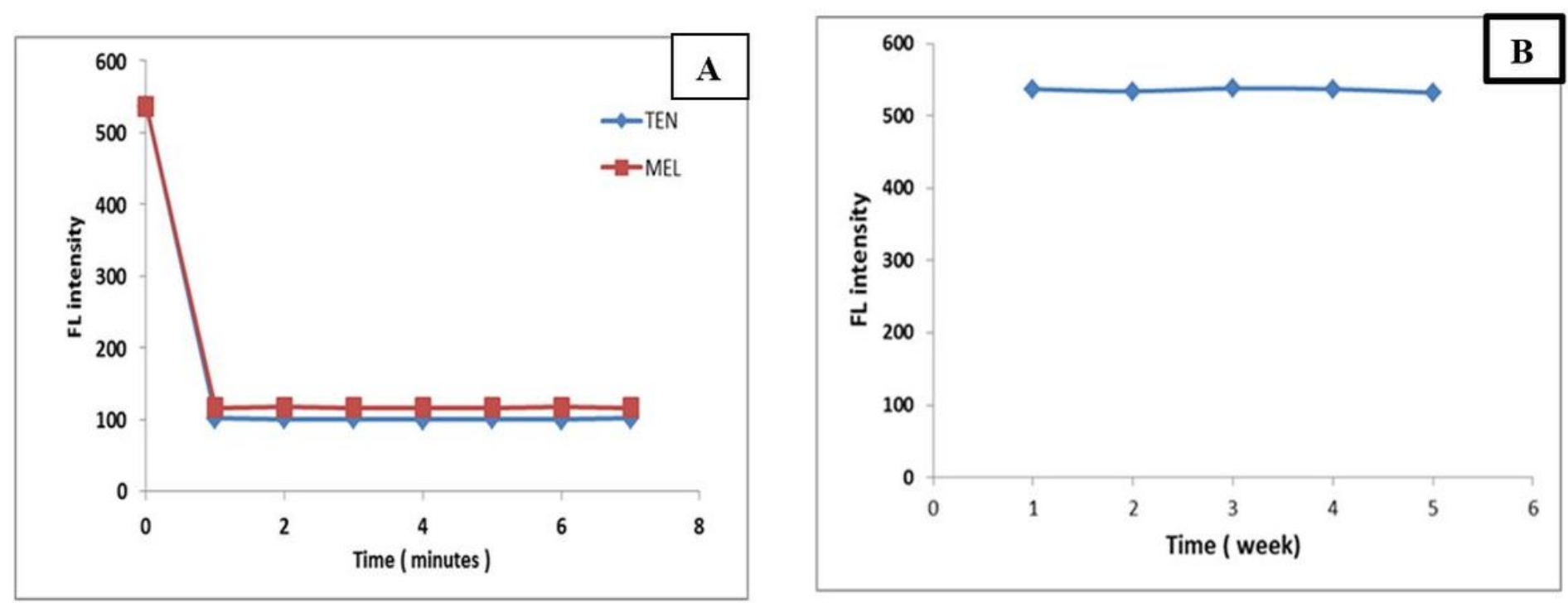

Figure 4

(A) The response time of the developed sensing system at concentration $30.0 \mu \mathrm{g} / \mathrm{mL}$ of TEN or MEL and (B) Stability of the isolated CMTS within 5 weeks.
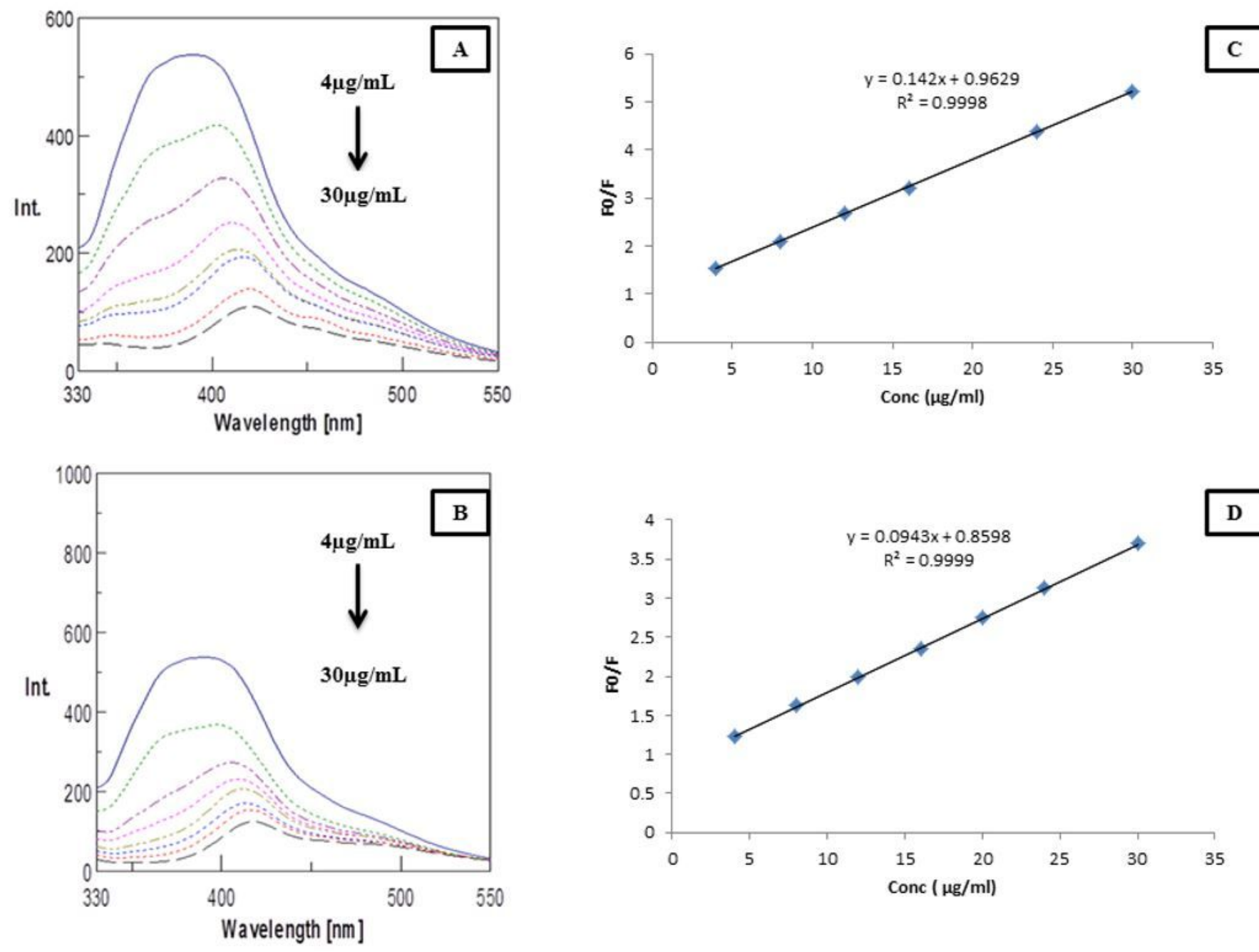
Figure 5

Fluorescence spectra of the isolated CMTS in the presence of different concentration of (A) TEN (4.0 $\mu \mathrm{g} / \mathrm{mL}$ to $30.0 \mu \mathrm{g} / \mathrm{mL})$ and (B) MEL $(4.0 \mu \mathrm{g} / \mathrm{mL}$ to $30.0 \mu \mathrm{g} / \mathrm{mL})$ from top to bottom, Calibration curve of (C) TEN and (D) MEL.
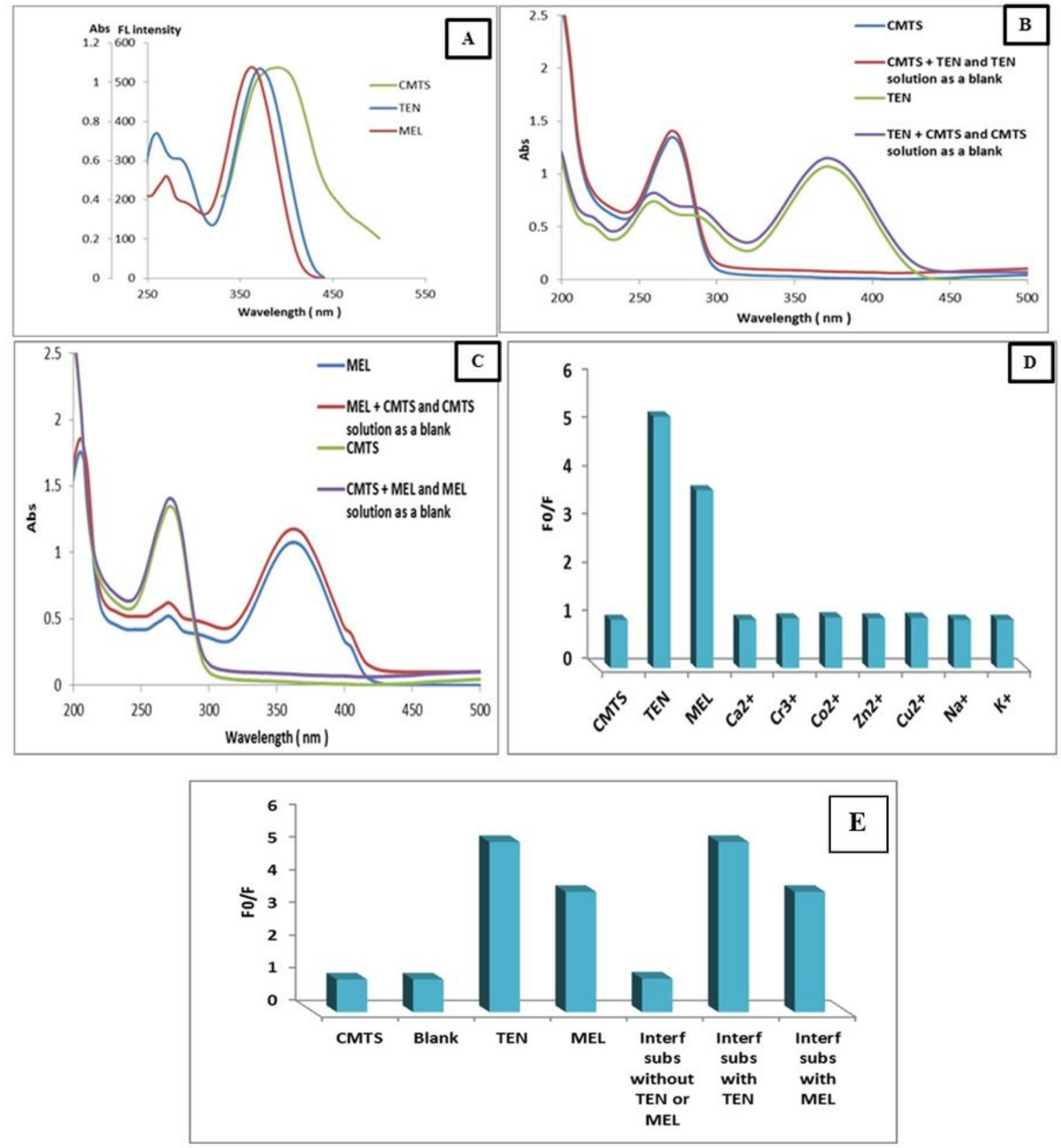

Figure 6 
(A) Overlap of the emission spectrum of The isolated CMTS and the absorption spectra of TEN and MEL, (B) The absorption spectra of the isolated CMTS and TEN before and after mixing, (C) The absorption spectra of the isolated CMTS and MEL before and after mixing, (D) Individual Interference of various Substances in estimation of TEN and MEL and (E) Fluorescence response of TEN or MEL and mixtures of interfering substances in absence and presence of TEN or MEL. 